\title{
Hepatocellular cancer and colorectal liver metastasis treatment in the older population
}

\author{
Jakub Kenig \\ Department of General, Gastrointestinal, Oncologic Surgery and Transplantology, I Chair of General Surgery, \\ Jagiellonian University Medical College, Krakow, Poland
}

\begin{abstract}
More than $60 \%$ of patients with primary and secondary liver tumors are older than 65 years. Thanks to improvements in radiological staging, anesthesia, surgical technique, and perioperative care it is possible to offer complex liver surgery to older patients. However, chronological age or functional status alone should not be a contraindication for multimodal radical treatment in older patients. Fit patients, according to the Comprehensive Geriatric Assessment, should be qualified for the same treatment as younger patients to ensure the same outcomes. Prefrail patients should undergo prehabilitation, and be reevaluated. Frail patients should be discussed in an oncogeriatric meeting. All patients with liver malignant tumors must be operated on in high-volume hospitals by an experienced surgeon. The introduction of parenchymal sparing surgery (instead of a major resection) in combination with other treatment tools, minimal invasive techniques, and enhanced postoperative recovery demonstrated being beneficial for older patients. In particular, frail, older patients can benefit from the wide variety of treatment options.
\end{abstract}

Key words: hepatocellular cancer, colorectal liver metastasis, older population, liver resection

The key components of successful oncologic liver surgery are: the ability to achieve an $\mathrm{R} 0$ resection, to maintain an appropriate vasculature and biliary system and to leave a sufficient functional liver parenchyma [1]. Thanks to improvements in radiological staging, anesthesia, surgical technique (understanding of segmental liver anatomy, parenchymal preserving surgery, bleeding control), and perioperative care it was possible to offer complex liver surgery to older patients. This is particularly important because, more than $60 \%$ of patients with primary and secondary liver tumors are older than 65 years at the moment of diagnosis [2].

At present, there are no treatment guidelines dedicated to older patients. The main reason for this situation is still the underrepresentation of older patients in trials regarding liver resection. In the majority of the published studies, only $15-20 \%$ of patients were older than 70 years [2]. Therefore, the extrapolation of such results on the geriatric population can lead to inappropriate treatment decisions.

\section{Normal aging of the liver}

Several age-related changes can be observed in liver physiology. The most important are: a decrease in liver weight and volume (up to 25\%), decrease in the hepatic blood flow (up to $40 \%$ ), an increase in the hepatic dense body compartment, shifts in the expression of a variety of proteins, and a decrease in bile flow and bile acid secretion [3-8]. These changes influence the liver's metabolic function, regeneration capacity, and immunity [3-8], which, in turn, may result in an increased risk

\section{How to cite:}

Kenig J. Hepatocellular cancer and colorectal liver metastasis treatment in the older population. NOWOTWORY J Oncol 2022; 72: 52-57. 
of postoperative liver failure, drug-induced liver damage, and sepsis [3-10]. 25-30\% of a total healthy liver volume needs to be preserved after the resection. However, in the case of patients with liver cirrhosis, steatosis or fibrosis, a larger remnant of the organ needs to be intact. Despite preoperative evaluations, liver failure occurs in up to $5 \%$ patients in the postoperative period, particularly often in older patients [11]. Tzend et al. did not observe a significant difference in the preoperative LiMAx liver function between young and older patients. However, liver regeneration is significantly different in older population in the early period. Age was inversely correlated with liver regeneration potential during the first postoperative week, without any difference between young and older patients after one month [12]. None of the studies analyzed the biologic age.

\section{Preoperative assessment and treatment decisions}

As was mentioned in our previous publications, the population of older patients is very heterogeneous in terms of co-morbidity, physical reserve, cognitive function, and social support. Chronological age alone is a poor predictor of cancer treatment outcomes and toxicities [13]. Current routine pre-operative assessments cannot adequately identify patients at risk. Many older adults have unidentified, uncommunicated, and therefore unaddressed aging-related conditions that are associated with poorer outcomes. As a result, the Comprehensive Geriatric Assessment (CGA) was introduced to help determine the primary status of the older patient, to diagnose frailty syndrome, and to identify how to optimize the patient's condition before the start of treatment [14-16]. Therefore, more and more organisations, including the International Society of Geriatric Oncology, the National Comprehensive Network, the European Organisation for the Research and Treatment of Cancer, the American College of Surgeons National Surgical Quality Improvement Program, and the American Geriatric Society have called for the routine use of the Geriatric Assessment.

Rostoft et al. analyzed the literature regarding the role of the CGA in predicting the outcome in hepatobiliary and pancreatic surgery among older patients with cancer. It was concluded that although there are not many studies, frailty and elements from the CGA are significantly associated with negative short- and long-term treatment outcomes in older patients with hepatobiliary and pancreatic cancers [17].

\section{Clinical characteristics of older HCC patients}

Hepatocellular carcinoma (HCC) is the primary tumor of the liver with the greatest incidence worldwide. It is the fifth most common neoplasm and the third highest cause of cancer-related mortality [18]. The risk of developing HCC increases with age, reaching the highest incidence in the geriatric population during the seventh decade of life. Moreover, improvements in the treatment of chronic liver disease have caused an increase in the number of potential patients who may develop
HCC [19]. In Europe, HCC older patients are more likely to be women and to be infected with HCV, less common with HBV. Moreover, in older patients, HCC develops more commonly in healthy livers [19]

\section{Liver surgery in older patients with HCC}

The Barcelona Clinic Liver Cancer (BCLC) stage system is the most used tool for treatment planning in patients with HCC. Based on the characteristics of the tumor, the degree of liver failure and physical condition, patients are stratified into five categories:

- very early (BCLC 0),

- early (BCLC A),

- intermediate (BCLC B),

- advanced (BCLCC),

- terminal (BCLC D).

For the two first stages (BCLC stage 0 and $A$ ), there is a wide range of treatment options including liver resection, liver transplantation, and local ablation. In the BCLC B stage, transarterial chemoembolization is usually proposed. In turn, in the BCLC C stage patients are qualified for treatment with Sorafenib. In the terminal stage (BCLC D), the best supportive treatment seems the optimal option [20]. There are also other staging systems. However, none of them is using the comprehensive geriatric assessment caps earlier or any other geriatric scale that allows determining frailty.

Concluding recently published studies on older populations undergoing various liver resections due to HCC, the morbidity and mortality rates ranged from $9 \%$ to $51 \%$ and from $0 \%$ to $7.5 \%$, respectively. In high volume hospitals, there was no difference between younger and older patients in short-term morbidity, mortality, and length of hospital stay [21-23]. The 5-year overall survival rate ranged between 26\% and even $75.9 \%$ in well-selected older patients. However, surgical treatment was only possible in up to $14 \%$ of older patients, compared with the younger group (12-28\%) [24-27].

The introduction of parenchymal sparing surgery resulted in a decrease in mortality in older patients compared with older patients undergoing major hepatectomy [28]. In experienced hands, laparoscopic and robotic techniques further reduce surgical stress and improve the outcomes. Reported morbidity ranges were 10-15\% and mortality was around 1\%, respectively [29]. However, when analyzing the outcomes, various selection bias must be considered. A systematic review and meta-analysis, published in 2019, showed no significant difference in terms of blood loss, transfusions, liver failure, Clavien-Dindo III/IV complications, postoperative mortality, hospital stay, R0 resection, and operative time between younger and older patients undergoing laparoscopic hepatectomy [29]. Moreover, the minimal invasive approach in HCC cirrhotic patients has also the potential to reduce risk of post-operative liver decompensation and morbidities [30, 31]. However, most of the studied patients were evaluated based on chronological 
age, comorbidities, and physical function - not on the comprehensive geriatric assessment.

\section{Liver transplant in older patients}

Data from the United Network for Organ Sharing and the European LiverTransplant Registry show a significant increase in the number of patients over 70 years with end-stage liver disease who qualified for a liver transplant in the last decade; it was also one of the fastest-growing patient populations [32]. In the 2019 systematic review and meta-analysis, Gavara et al. did observe acceptable short- and long-term results. They also did not find any difference in the risk of complications between young and older patients [33]. Although long-term liver transplant results are very good, older patients are rarely qualified because of their low priority on the list of available organs $[32,33]$.

\section{Radiofrequency ablation for older HCC patients}

The European Association for the Study of the Liver (EASL) guidelines recommends RFA as a standard of care for patients with BCLC stage $0-A$, in the case of tumors not suitable for surgical resection [34, 35]. However, in the case of older patients, the results of published studies are inconsistent. Some of them report comparable outcomes between young and older population [36-38]. In turn, others reveal higher complication rates due to patients' comorbidities, use of antiplatelet or anticoagulant drugs, and preoperative low functional levels. The overall survival rates in the older group were significantly lower than those in the younger population and the recurrence-free survival rates were comparable [39].

\section{Transarterial chemoembolization for older HCC patients}

The transarterial chemoembolisation (TACE) is a procedure combing the transcatheter delivery of an anticancer drug into the hepatic artery followed by vascular obstruction with embolic agents [40]. Current guidelines recommend TACE as the standard of care for patients with multinodular, asymptomatic tumors without vascular invasion or extrahepatic spread (BCLC stage B tumors). Recent studies showed that the TACE is a safe and effective treatment in older HCC patients. The morbidity rate ranged from $4.5 \%$ to $27 \%$, without any significant difference between older and younger patients, including also contrast medium-induced renal dysfunctions [41]. The 3-year and 5-year OS ranged between $14.9-48 \%$ and $8.4-33.8 \%$, respectively [42-44].

\section{Immunotherapy for older HCC patients}

Sorafenib has shown efficacy in two randomized trials, resulting in a significant 30\% improvement in survival of HCC patients [45]. The European Association for the Study of the Liver recommends sorafenib as the preferred treatment for patients with HCC who cannot tolerate potentially more effective therapies, particularly in the case of preserved liver function (Child-Pugh grade A) and advanced tumor stages (BCLC stage C) [46]. In the case of the older population, it turned out to be equally safe among older and younger patients with similar toxicity-related discontinuation rates between these groups [47]. There was also no difference between these groups regarding overall survival and time to treatment failure [48]. After 10 years, another multikinase inhibitor, Lenvatinib, was approved in first-line treatment [49]. Studies have proven its non-inferiority compared with sorafenib in cases of overall survival. Moreover, lenvatinib may have some potential benefits over sorafenib for patients with HBV chronic infection [49]. Atezolizumab plus bevacizumab as first-line treatment is the next treatment possibility in the treatment of advanced HCC [50]. However, we have to wait for further studies including those on the geriatric population.

Concluding, we need well-designed studies on a larger group of older patients using various advances of geriatric oncology. The Comprehensive Geriatric Assessment, evaluation of life expectancy, and analysis of patients' goals should become routine preoperative instruments allowing for better selection of older patients for a tailored treatment. They are proven to correlate much more with the short- and long-term outcomes in comparison to the currently evaluated factors. Therefore, Suda et al. proposed the percent life expectancy (\%LE). It is the survival time for each patient divided by the life expectancy. This parameter may evaluate the benefits of a given treatment for older HCC patients. The authors showed that patients aged 80 years or older had the best survival benefit according to the \%LE [52].

Moreover, there are currently many unintentional selections bias in most of the studies. The physicians tend to qualify older patients for surgical treatment with a good performance status and preserved liver function. This might favor similar outcomes to those of younger patients. In turn, the chronologically oldest patients are often qualified for non-curative treatment, which might favor poorer prognosis compared with younger patients [51].

\section{Colorectal liver metastasis in older patients}

Recent studies have shown that patients aged 70 and more who undergo liver resection for colorectal liver metastases have the possibility to achieve a 5-year survival of $21-44 \%$, with postoperative morbidity and mortality rates of approximately $20-40 \%$ and $0-7 \%$, respectively. This is despite patients undergoing more complex treatment for more extensive disease [53-62]. The main reason for the outcome improvement is the introduction of parenchymal sparing liver surgery. It has been shown to be associated with less surgical stress, fewer postoperative complications, non-inferior cancer-related outcomes, and higher feasibility of future resections [63]. There is also a higher rate of $\mathrm{R} 1$ resection. However, it is not associated with poorer disease free survival $[64,65]$. Therefore, major 
resection should be limited only to patients where it is the only curative option.

More and more older patients are getting neoadjuvant chemotherapy with intend to downstage the disease and to converse the disease into resectable. It has been proven that chemotherapy in combination with surgical techniques was not associated with poorer postoperative outcomes in older patients in comparison to younger groups [66]. So, excellent perioperative outcomes can be achieved with morbidity and mortality of $38.2 \%$ and $0.3 \%$, respectively, using parenchymal sparing liver surgery, chemotherapy, and ablation. That combination should be used to avoid unnecessary major liver resection [67-71]. Implementation of the ERAS program in the postoperative period may further improve outcomes. A 2015 meta-analysis of randomized controlled trials on the efficacy of the ERAS program in liver surgery showed that this approach significantly reduces post-operative morbidity, length of stay, and accelerates functional recovery [72].

For older patients with unresectable CRLM who meet the eligibility criteria for radioembolization, 90 Y-radioembolisation microspheres appear to be effective and well-tolerated, regardless of age. Therefore, the selection of patients for radioembolization should not include chronological age as an exclusion factor [73].

\section{Conflict of interest: none declared}

\section{Jakub Kenig}

Jagiellonian University Medical College

Department of General, Oncologic, Gastrointestinal Surgery and Transplantology

I Chair of General Surgery

ul. Jakubowskiego 2

30-688 Kraków, Poland

e-mail:jkenig@cm-uj.krakow.pl

\section{Received: 30 Nov 2021}

Accepted: 24 Dec 2021

\section{References}

1. Orcutt ST, Anaya DA. Liver Resection and Surgical Strategies for Management of Primary Liver Cancer. Cancer Control. 2018; 25(1): 1073274817744621, doi: 10.1177/1073274817744621, indexed in Pubmed: 29327594

2. Federico P, Giunta EF, Pappalardo A, et al. How to Treat Hepatocellular Carcinoma in Elderly Patients. Pharmaceuticals (Basel). 2021; 14(3), doi: 10.3390/ph14030233, indexed in Pubmed: 33800217.

3. Marchesini G, Bua V, Brunori A, et al. Galactose elimination capacity and liver volume in aging man. Hepatology. 1988; 8(5): 1079-1083, doi: 10.1002/hep.1840080516, indexed in Pubmed: 3417228.

4. Jansen PLM. Liver disease in the elderly. Best Pract Res Clin Gastroenterol. 2002; 16(1): 149-158, doi: 10.1053/bega.2002.0271, indexed in Pubmed: 11977934

5. Frith J, Jones D, Newton JL. Chronic liver disease in an ageing population. Age Ageing. 2009; 38(1): 11-18, doi: 10.1093/ageing/afn242, indexed in Pubmed: 19029099.

6. Gan L, Chitturi S, Farrell GC. Mechanisms and implications of age-related changes in the liver: nonalcoholic Fatty liver disease in the elderly. Curr Gerontol Geriatr Res. 2011; 2011: 831536, doi: 10.1155/2011/831536, indexed in Pubmed: 21918648.

7. Wynne HA, Cope LH, Mutch E, et al. The effect of age upon liver volume and apparent liver blood flow in healthy man. Hepatology. 1989; 9(2): 297-301, doi: 10.1002/hep.1840090222, indexed in Pubmed: 2643548.
8. Zoli M, Magalotti D, Bianchi G, et al. Total and functional hepatic blood flow decrease in parallel with ageing. Age Ageing. 1999; 28(1): 29-33, doi: 10.1093/ageing/28.1.29, indexed in Pubmed: 10203201.

9. Schmucker DL, Gilbert R, Jones $A L$, et al. Effect of aging on the hepatobiliary transport of dimeric immunoglobulin $\mathrm{A}$ in the male Fischer rat. Gastroenterology. 1985; 88(2): 436-443, doi: 10.1016/00165085(85)90504-9, indexed in Pubmed: 3965333.

10. Brouwer A, Barelds RJ, Knook DL, et al. Maintenance cultures of Kupffer cells isolated from rats of various ages: ultrastructure, enzyme cytochemistry, and endocytosis. Hepatology. 1983; 3(4): 497-506, doi: 10.1002/ hep.1840030405, indexed in Pubmed: 6345331.

11. Farges O, Goutte N, Bendersky N, et al. ACHBT-French Hepatectomy Study Group. Incidence and risks of liver resection: an all-inclusive French nationwide study. Ann Surg. 2012; 256(5): 697-704; discussion 704, doi: 10.1097/SLA.0b013e31827241d5, indexed in Pubmed: 23095612.

12. Tzeng CWD, Cooper AB, Vauthey JN, et al. Predictors of morbidity and mortality after hepatectomy in elderly patients: analysis of 7621 NSQIP patients. HPB (Oxford). 2014; 16(5): 459-468, doi: 10.1111/hpb.12155, indexed in Pubmed: 24033514.

13. Kenig J. Oncogeriatrics (part 1.). Frailty in older adults with cancer. Nowotwory. Journal of Oncology. 2019; 69(2): 55-57, doi: 10.5603/ njo.2019.0010.

14. Loh KP, Soto-Perez-de-Celis E, Hsu T, et al. What Every Oncologist Should Know About Geriatric Assessment for Older Patients With Cancer:Young International Society of Geriatric Oncology Position Paper. J Oncol Pract. 2018; 14(2): 85-94, doi: 10.1200/JOP.2017.026435, indexed in Pubmed: 29436306.

15. Grodzicki T, Kenig J. Problemy okołooperacyjne u osób w wieku podeszłym. PZWL Wydawnictwo Lekarskie, Warszawa 2018.

16. Kenig J, Szabat K. Oncogeriatrics (part 7.). Geriatric assessment for older patients with cancer. Nowotwory. Journal of Oncology. 2020; 70(4): 153-157, doi: 10.5603/njo.2020.0031.

17. Rostoft $S$, van Leeuwen B. Frailty assessment tools and geriatric assessment in older patients with hepatobiliary and pancreatic malignancies. Eur J Surg Oncol. 2021; 47(3 Pt A): 514-518, doi: 10.1016/j. ejso.2020.08.024, indexed in Pubmed: 32933803.

18. Forner A, Llovet J, Bruix J. Hepatocellular carcinoma. The Lancet. 2012; 379(9822): 1245-1255, doi: 10.1016/s0140-6736(11)61347-0.

19. Bruix J, Gores GJ, Mazzaferro V. Hepatocellular carcinoma: clinical frontiers and perspectives. Gut. 2014; 63(5): 844-855, doi: 10.1136/ gutjnl-2013-306627, indexed in Pubmed: 24531850.

20. Oishi K, Itamoto T, Kohashi T, et al. Safety of hepatectomy for elderly patients with hepatocellular carcinoma. World J Gastroenterol. 2014; 20(41): 15028-15036, doi: 10.3748/wjg.v20.i41.15028, indexed in Pubmed: 25386051.

21. Wu CC, Chen JT, Ho WL, et al. Liver resection for hepatocellular carcinoma in octogenarians. Surgery. 1999; 125(3): 332-338, doi: 10.1016/ s0039-6060(99)70245-x.

22. Hazama H, Omagari K, Matsuo l, et al. Clinical features and treatment of hepatocellular carcinoma in eight patients older than eighty years of age. Hepatogastroenterology. 2001; 48(42): 1692-1696, indexed in Pubmed: 11813602.

23. Shirabe K, Kajiyama K, Harimoto N, et al. Early outcome following hepatic resection in patients older than 80 years of age. World J Surg. 2009; 33(9): 1927-1932, doi: 10.1007/s00268-009-0122-3, indexed in Pubmed: 19603226.

24. Nanashima A, Abo T, Nonaka T, et al. Prognosis of patients with hepatocellular carcinoma after hepatic resection: are elderly patients suitable for surgery? J Surg Oncol. 2011; 104(3): 284-291, doi: 10.1002/jso.21932, indexed in Pubmed: 21462192.

25. Yamada S, Shimada M, Miyake H, et al. Outcome of hepatectomy in super-elderly patients with hepatocellular carcinoma. Hepatol Res. 2012; 42(5): 454-458, doi: 10.1111/j.1872-034X.2011.00952.x, indexed in Pubmed: 22295877.

26. Tsujita E, Utsunomiya T, Yamashita Y, et al. Outcome of hepatectomy in hepatocellular carcinoma patients aged 80 years and older. Hepatogastroenterology. 2012; 59: 1553.

27. Katsuta E, Tanaka S, Mogushi K, et al. Age-related clinicopathologic and molecular features of patients receiving curative hepatectomy for hepatocellular carcinoma. Am J Surg. 2014; 208(3): 450-456, doi: 10.1016/j.amjsurg.2014.01.015, indexed in Pubmed: 24972857.

28. Nozawa A, Kubo S, Takemura S, et al. Hepatic resection for hepatocellular carcinoma in super-elderly patients aged 80 years and older in the first decade of the 21 st century. Surg Today. 2015; 45(7): 851-857, doi: 10.1007/s00595-014-0994-1, indexed in Pubmed: 25113072.

29. Notarnicola M, Felli E, Roselli S, et al. Laparoscopic liver resection in elderly patients: systematic review and meta-analysis. Surg Endosc. 
2019; 33(9): 2763-2773, doi: 10.1007/s00464-019-06840-9, indexed in Pubmed: 31139986.

30. Sahara K, Paredes AZ, Tsilimigras DI, et al. Impact of Liver Cirrhosis on Perioperative Outcomes Among Elderly Patients Undergoing Hepatectomy: the Effect of Minimally Invasive Surgery. J Gastrointest Surg. 2019; 23(12): 2346-2353, doi: 10.1007/s11605-019-04117-z, indexed in Pubmed: 30719676.

31. Federico P, Giunta EF, Pappalardo A, et al. How to Treat Hepatocellular Carcinoma in Elderly Patients. Pharmaceuticals (Basel). 2021; 14(3), doi: 10.3390/ph14030233, indexed in Pubmed: 33800217.

32. Dolnikov $S$, Adam $R$, Cherqui $D$, et al. Liver transplantation in elderly patients: what do we know at the beginning of 2020? Surg Today. 2020; 50(6): 533-539, doi: 10.1007/s00595-020-01996-7, indexed in Pubmed: 32279191.

33. Gómez Gavara C, Esposito F, Gurusamy K, et al. Liver transplantation in elderly patients: a systematic review and first meta-analysis. HPB (Oxford). 2019; 21(1): 14-25, doi: 10.1016/j.hpb.2018.07.025, indexed in Pubmed: 30146227.

34. Bruix J, Sherman M. American Association for the Study of Liver Diseases. Management of hepatocellular carcinoma: an update. Hepatology. 2011; 53(3): 1020-1022, doi: 10.1002/hep.24199, indexed in Pubmed: 21374666.

35. Cucchetti A, Piscaglia F, Cescon M, et al. Systematic review of surgical resection vs radiofrequency ablation for hepatocellular carcinoma. World J Gastroenterol. 2013; 19(26): 4106-4118, doi: 10.3748/wjg.v19. i26.4106, indexed in Pubmed: 23864773.

36. Hiraoka A, Michitaka K, Horiike N, et al. Radiofrequency ablation therapy for hepatocellular carcinoma in elderly patients. J Gastroenterol Hepatol. 2010; 25(2): 403-407, doi: 10.1111/j.1440-1746.2009.06037.x, indexed in Pubmed: 19929922.

37. Takahashi H, Mizuta T, Kawazoe S, et al. Efficacy and safety of radiofrequency ablation for elderly hepatocellular carcinoma patients. Hepatol Res. 2010; 40(10): 997-1005, doi: 10.1111/j.1872-034X.2010.00713.x, indexed in Pubmed: 20887335.

38. Yamazaki H, Tsuji K, Nagai K, et al. Efficacy and long-term outcomes of radiofrequency ablation in the elderly with hepatocellular carcinoma. Hepatol Res. 2014;44(11): 1095-1101, doi: 10.1111/hepr.12233, indexed in Pubmed: 24033930.

39. Zhang F, Wu G, Sun $\mathrm{H}$, et al. Radiofrequency ablation of hepatocellular carcinoma in elderly patients fitting the Milan criteria: a single centre with 13 years experience. Int J Hyperthermia. 2014; 30(7): 471-479, doi: 10.3109/02656736.2014.961042, indexed in Pubmed: 25314335.

40. Yau T, Yao TJ, Chan P, et al. The outcomes of elderly patients with hepatocellular carcinoma treated with transarterial chemoembolization. Cancer. 2009; 115(23): 5507-5515, doi: 10.1002/cncr.24636, indexed in Pubmed: 19701904

41. Cohen MJ, Levy I, Barak O, et al. Trans-arterial chemo-embolization is safe and effective for very elderly patients with hepatocellular carcinoma. World J Gastroenterol. 2013; 19(16): 2521-2528, doi: 10.3748/ wjg.v19.i16.2521, indexed in Pubmed: 23674854.

42. Cohen MJ, Levy I, Barak O, et al. Trans-arterial chemo-embolization is safe and effective for elderly advanced hepatocellular carcinoma patients: results from an international database. Liver Int. 2014; 34(7): 1109-1117, doi: 10.1111/liv.12486, indexed in Pubmed: 24512125.

43. Nishikawa H, Kita R, Kimura T, et al. Transcatheter arterial chemoembolization for intermediate-stage hepatocellular carcinoma: clinical outcome and safety in elderly patients. J Cancer. 2014; 5(7): 590-597, doi: 10.7150/jca.9413, indexed in Pubmed: 25057310.

44. Golfieri R, Bilbao Jl, Carpanese L, et al. European Network on Radioembolization with Yttrium-90 Microspheres (ENRY) study collaborators. Comparison of the survival and tolerability of radioembolization in elderly vs. younger patients with unresectable hepatocellular carcinoma. J Hepatol. 2013; 59(4): 753-761, doi: 10.1016/j.jhep.2013.05.025, indexed in Pubmed: 23707371.

45. Guilherme NM, da Fonseca LG, Braghiroli MG, et al. Efficacy and safety of sorafenib in elderly patients with advanced hepatocellular carcinoma. Clinics. 2021; 76: 123-130.

46. Wong $\mathrm{H}$, Tang YF, Yao TJ, et al. The outcomes and safety of single-agent sorafenib in the treatment of elderly patients with advanced hepatocellular carcinoma (HCC). Oncologist. 2011; 16(12): 1721-1728, doi: 10.1634/theoncologist.2011-0192, indexed in Pubmed: 22135121.

47. Di Costanzo GG, Tortora R, De Luca M, et al. Impact of age on toxicity and efficacy of sorafenib-targeted therapy in cirrhotic patients with hepatocellular carcinoma. Med Oncol. 2013; 30(1): 446, doi: 10.1007/ s12032-012-0446-y, indexed in Pubmed: 23307255.

48. Jo M, Yasui K, Kirishima T, et al. Efficacy and safety of sorafenib in very elderly patients aged 80 years and older with advanced hepatocel- lular carcinoma. Hepatol Res. 2014; 44(13): 1329-1338, doi: 10.1111/ hepr.12308, indexed in Pubmed: 24528772.

49. Morimoto $\mathrm{M}$, Numata $\mathrm{K}$, Kondo $\mathrm{M}$, et al. Higher discontinuation and lower survival rates are likely in elderly Japanese patients with advanced hepatocellular carcinoma receiving sorafenib. Hepatol Res. 2011; 41(4): 296-302, doi: 10.1111/j.1872-034X.2011.00778.x, indexed in Pubmed: 21348907.

50. Edeline J, Crouzet L, Le Sourd S, et al. Sorafenib use in elderly patients with hepatocellular carcinoma: caution about use of platelet aggregation inhibitors. Cancer Chemother Pharmacol. 2015; 75(1): 215-219, doi: 10.1007/s00280-014-2645-z, indexed in Pubmed: 25477009.

51. Kinoshita A, Koike K, Nishino H. Clinical features and prognosis of elderly patients with hepatocellular carcinoma not indicated for surgical resection. Geriatr Gerontol Int. 2017; 17(2): 189-201, doi: 10.1111/ggi.12747, indexed in Pubmed: 26847184.

52. Suda T, Nagashima A, Takahashi S, et al. Active treatments are a rational approach for hepatocellular carcinoma in elderly patients. World J Gastroenterol. 2013; 19(24): 3831-3840, doi: 10.3748/wjg.v19.i24.3831, indexed in Pubmed: 23840122.

53. Cho SW, Steel J, Tsung A, et al. Safety of liver resection in the elderly: how important is age? Ann Surg Oncol. 2011; 18(4): 1088-1095, doi: 10.1245/s10434-010-1404-6, indexed in Pubmed: 21046265.

54. de Liguori Carino N, van Leeuwen BL, Ghaneh $\mathrm{P}$, et al. Liver resection for colorectal liver metastases in older patients. Crit Rev Oncol Hematol. 2008; 67(3): 273-278, doi: 10.1016/j.critrevonc.2008.05.003, indexed in Pubmed: 18595728.

55. Figueras J, Ramos E, López-Ben S, et al. Surgical treatment of liver metastases from colorectal carcinoma in elderly patients. When is it worthwhile? Clin Transl Oncol. 2007; 9(6): 392-400, doi: 10.1007/ s12094-007-0072-x, indexed in Pubmed: 17594954.

56. Menon KV, Al-Mukhtar A, Aldouri A, et al. Outcomes after major hepatectomy in elderly patients. J Am Coll Surg. 2006; 203(5): 677-683, doi: 10.1016/j.jamcollsurg.2006.07.025, indexed in Pubmed: 17084329.

57. Adam R, Frilling A, Elias D, et al. LiverMetSurvey Centres. Liver resection of colorectal metastases in elderly patients. Br J Surg. 2010; 97(3): 366-376, doi: 10.1002/bjs.6889, indexed in Pubmed: 20101645.

58. Cannon RM, Martin RCG, Callender GG, et al. Safety and efficacy of hepatectomy for colorectal metastases in the elderly. J Surg Oncol. 2011; 104(7): 804-808, doi: 10.1002/jso.22042, indexed in Pubmed: 21792943.

59. Orcutt ST, Artinyan A, Li LT, et al. Postoperative mortality and need for transitional care following liver resection for metastatic disease in elderly patients: a population-level analysis of 4026 patients. HPB (Oxford). 2012; 14(12): 863-870, doi: 10.1111/j.1477-2574.2012.00577.x, indexed in Pubmed: 23134189.

60. Mann CD, Neal CP, Pattenden CJ, et al. Major resection of hepatic colorectal liver metastases in elderly patients - an aggressive approach is justified. Eur J Surg Oncol. 2008; 34(4): 428-432, doi: 10.1016/j. ejso.2007.03.013, indexed in Pubmed: 17466484.

61. Hutchins LF, Unger JM, Crowley JJ, et al. Underrepresentation of patients 65 years of age or older in cancer-treatment trials. N Engl J Med. 1999; 341(27): 2061-2067, doi: 10.1056/NEJM199912303412706, indexed in Pubmed: 10615079.

62. Song W, Wang K, Zhang RJ, et al. The enhanced recovery after surgery (ERAS) program in liver surgery: a meta-analysis of randomized controlled trials. Springerplus. 2016; 5: 207, doi: 10.1186/s40064-016-1793-5, indexed in Pubmed: 27026903.

63. Van Cutsem E, Cervantes A, Adam R, et al. ESMO consensus guidelines for the management of patients with metastatic colorectal cancer. Ann Oncol. 2016; 27(8): 1386-1422, doi: 10.1093/annonc/mdw235, indexed in Pubmed: 27380959.

64. Rinaldi F, George E, Adler Al. NICE guidance on cetuximab, bevacizumab, and panitumumab for treatment of metastatic colorectal cancer after first-line chemotherapy. Lancet Oncol. 2012; 13(3): 233-234, doi: 10.1016/s1470-2045(12)70044-x, indexed in Pubmed: 22489288.

65. Tufo A, Dunne DFj, Manu N, et al. Changing outlook for colorectal liver metastasis resection in the elderly. Eur J Surg Oncol. 2019; 45(4): 635-643, doi: 10.1016/j.ejso.2018.11.024, indexed in Pubmed: 30553630.

66. Kanas GP, Taylor A, Primrose JN, et al. Survival after liver resection in metastatic colorectal cancer: review and meta-analysis of prognostic factors. Clin Epidemiol. 2012; 4: 283-301, doi: 10.2147/CLEP.S34285, indexed in Pubmed: 23152705.

67. Kopetz S, Chang GJ, Overman MJ, et al. Improved survival in metastatic colorectal cancer is associated with adoption of hepatic resection and improved chemotherapy. J Clin Oncol. 2009; 27(22): 3677-3683, doi: 10.1200/JCO.2008.20.5278, indexed in Pubmed: 19470929. 
68. Taner T, Atwell TD, Zhang L, et al. Adjunctive radiofrequency ablation of metastatic neuroendocrine cancer to the liver complements surgical resection. HPB (Oxford). 2013; 15(3): 190-195, doi: 10.1111/j.1477-2574.2012.00528.x, indexed in Pubmed: 23374359.

69. Mohan $\mathrm{H}$, Nicholson $\mathrm{P}$, Winter DC, et al. Radiofrequency ablation for neuroendocrine liver metastases: a systematic review. J Vasc Interv Radiol. 2015; 26(7): 935-942.e1, doi: 10.1016/j.jvir.2014.12.009, indexed in Pubmed: 25840836.

70. Baere Tde, Deschamps F, Tselikas L, et al. GEP-NETS UPDATE: Interventional radiology: role in the treatment of liver metastases from GEP-NETs. European Journal of Endocrinology. 2015; 172(4): R151-R166, doi: 10.1530/eje-14-0630.
71. Song W, Wang K, Zhang RJ, et al. The enhanced recovery after surgery (ERAS) program in liver surgery: a meta-analysis of randomized controlled trials. Springerplus. 2016; 5: 207, doi: 10.1186/s40064-016-1793-5, indexed in Pubmed: 27026903.

72. Kennedy AS, Ball DS, Cohen SJ, et al. Metastatic Colorectal Cancer Liver Metastases Outcomes After Radioembolization (MORE) Study Investigators. Safety and Efficacy of Radioembolization in Elderly ( $\geq 70$ Years) and Younger Patients With Unresectable Liver-Dominant Colorectal Cancer. Clin Colorectal Cancer. 2016; 15(2): 141-151.e6, doi: 10.1016/j. clcc.2015.09.001, indexed in Pubmed: 26541321. 